
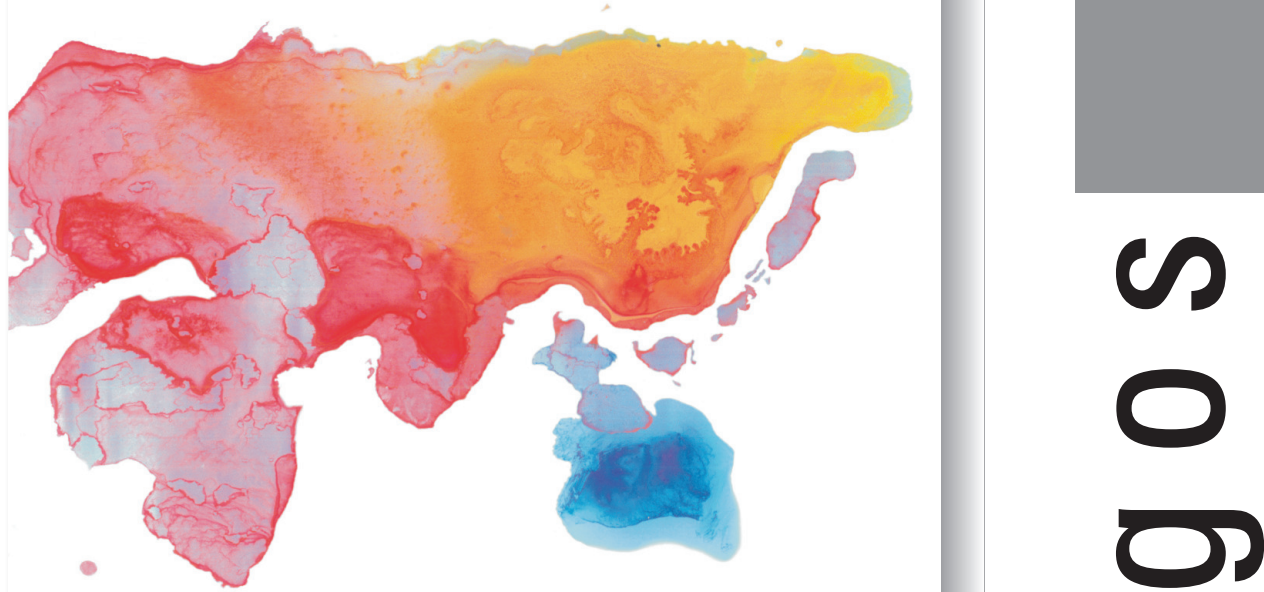

$\square$
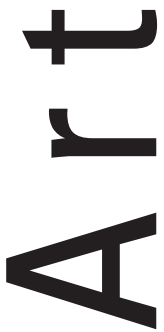


\title{
Capacidade de uso das terras como suporte ao planejamento ambiental na bacia hidrográfica do ribeirão Santo Antônio - Iporá-Go
}

\author{
Capacity of use of lands as has supported to the ambient planning in basin hydrográfic of the brook \\ saint Antonio - Iporá-Go
}

Flávio Alves de Sousa

flaueg@hotmail.com

Cláudia Valéria de Lima

flaueg@hotmail.com

\section{Resumo}

Diante das grandes transformações que estão ocorrendo no espaço geográfico, sobretudo em ambientes rurais, onde a demanda pela produção de alimentos se faz de maneira cada vez mais intensa, o planejamento de ações exploratórias dos recursos naturais, principalmente solos e água, se torna cada vez mais necessário, na tentativa de minimizar, ou mesmo resolver problemas ambientais ligados à exploração irracional dos recursos que garantam a nossa sobrevivência. Diante disso, o presente artigo trata sobre a importância de se avaliar a capacidade de uso das terras em bacias hidrográficas para melhor planejar ações ligadas à produtividade e à preservação dos recursos naturais para esta e para as gerações futuras. Discute, ainda as etapas necessárias para a elaboração da carta de capacidade de uso da terra e apresenta um estudo de caso na bacia do Ribeirão Santo Antônio no município de Iporá, Estado de Goiás, Brasil.

Palavras-chave: planejamento, recursos naturais, bacia hidrográfica

\begin{abstract}
Ahead of the great transformations that are occurring in the geographic space, over all in agricultural environments, whose demand for the food production if gives in way each more intense time, the planning of actions that uses the natural resources, mainly ground and water, if becomes each time more necessary, in the attempt to minimize or same to decide on ambient problems to exploration irrational of the resources that guarantee our survival. Ahead to this, the present article deals with on importance if evaluating the capacity of use of lands in hydrographic basins, better to plan on actions to the productivity and the preservation of natural resources, for this, and the future generations. It still argues the steps that if must give in the elaboration of such study, and presents a study of case in the basin of the brook Saint Antonio, in the city of Iporá, State of Goiás, Brazil.
\end{abstract}

Keywords: Management, natural resurces, hydrografic basin

\begin{tabular}{|l|c|c|c|c|c|c|}
\hline Boletim Goiano de Geografia & Goiânia - Goiás - Brasil & v. 27 & n. 3 & p. 91-101 & jul. / dez. & 2007 \\
\hline
\end{tabular}





\section{Introducão}

A bacia hidrográfica do Ribeirão Santo Atônio se localiza entre os paralelos $16^{\circ} 19^{\prime} 45^{\prime \prime}$ e $16^{\circ} 42^{\prime} 05^{\prime \prime}$ Sul, e os meridianos $51^{\circ} 04^{\prime} 30^{\prime \prime}$ e $51^{\circ} 23^{\prime} 27^{\prime \prime}$ Oeste. Abrange três municípios da região Oeste do Estado de Goiás (Iporá, Amorinópolis e Ivolândia) e apresenta uma área total de $650 \mathrm{Km} 2$, sendo que cerca de $75 \%$ (setenta e cinco por cento) desta área se encontra no município de Iporá. A área da bacia está representada nas Folhas Topográficas SE-22-V-B-III (Iporá) e SE-22-V-B-IV (Amorinópolis), ambas editadas pelo IBGE (Figura 1).

O presente artigo é parte dos resultados de um estudo sobre o uso e ocupação na bacia hidrográfica do Ribeirão Santo Antônio no município de Iporá, Estado de Goiás, que teve por objetivo principal avaliar as características físicas e a sua ocupação atual, bem como avaliar o grau de conservação de seus principais recursos naturais. Este trabalho é, então, uma tentativa de gerar maiores informações sobre a forma de exploração racional do meio físico na bacia hidrográfica do Ribeirão Santo Antônio, uma vez que a mesma representa a fonte de abastecimento de água para o município de Iporá, e que sabemos estar bastante comprometida com a má utilização das terras e a retirada maciça da cobertura vegetal nativa.

\section{Aspectos físicos da bacia}

A área apresenta uma paisagem bastante complexa, com variações litológicas que alteram as feições dos solos, da vegetação e do relevo, bem como da própria rede de drenagem. Entretanto, a sua diversificação fisionômica e morfológica interfere diretamente no uso e ocupação das terras, que, por isso, mesmo requerem uma maior atenção.

\section{Geologia}

A geologia local compreende uma grande variedade de rochas de idades variadas, que vão do Pré-cambriano até coberturas quaternárias. Neste contexto, destacam-se terrenos do Complexo granítico-gnaissico representados principalmente por rochas graníticas, que ocupam a área central da bacia. 
A Seqüência Meta-Vulcano-Sedimentar Iporá-Amorinópolis (Neoproterozóico) engloba rochas metavulcânicas básicas e ácidas associadas com metassedimentos (Moreton, 1999), ocorrem na porção sul da bacia, nas proximidades da cidade de Amorinópolis, e se estendem na direção norte em uma faixa estreita da bacia.

Os granitos Tipo Iporá (Neoproterozóico) exibem corpos de amplas variedades petrográficas e ocupam quase a totalidade da porção norte da bacia, às vezes, em contato com litologias sedimentares e vulcânicas básicas.

O Grupo Paraná (Paleozóico - Devoniano) está representado pelas Formações Furnas e Ponta Grossa. A Formação Furnas ocorre em porções variadas na área de estudo, intercalada com litologias diversas. Rochas da Formação Ponta Grossa aparecem disseminadas em todos os quadrantes da bacia, ora em afloramentos contínuos (oeste da bacia), ora intercalados a litologias de constituição e idades diversas.

O Grupo Iporá (Mesozóico - Cretáceo) caracteriza-se por ocorrências de rochas vulcânicas e intrusivas de natureza alcalina e, na área de estudo, afloram principalmente na porção N-NE em pequenas manchas, estando, quase sempre, em contato com as Formações Furnas e Ponta Grossa.

As Coberturas Detrítico-Lateríticas (Cenozóico) ocorrem de forma dispersa em alguns pontos da bacia, tendo maior área de exposição nos domínios dos terrenos granítico-gnáissicos e vulcano-sedimentares.

\section{Geomorfologia}

A geomorfologia na bacia do Ribeirão Santo Antônio apresenta três unidades geomorfológicas regionais, unidades estas definidas pelos estudos geomorfológicos do Projeto Radambrasil, representados na Folha SE.22 (Goiânia), quais sejam: Planalto Central Goiano, representado pelo Planalto do Alto Tocantins-Araguaia; Planaltos e Chapadas da Bacia Sedimentar do Paraná, representado pelo Planalto Setentrional da Bacia do Paraná e Depressão do Araguaia.

A partir da análise do mapa hipsométrico que foi elaborado com a finalidade de auxiliar na compreensão da geomorfologia local, foi possível verificar que a área apresenta altitudes que variam de 400 a 750 m, e que as menores cotas de altitude se encontram na parte central da bacia, coincidindo com o maior grau de entalhamento do relevo, determinado pela drenagem do Ribeirão Santo Antônio. 
Com o auxílio de imagem de satélite Landsat 7 TM, foi possível reconhecer as principais feições de relevo presentes na bacia, onde predominam relevos de topos aguçados, convexos, planos ou tabulares.

Finalmente, foi construído o mapa geomorfológico da área, na qual foram representadas as grandes unidades geomorfológicas regionais derivadas do mapeamento do Projeto Radambrasil Folha SE.22 (Goiânia) e também os compartimentos geomorfológicos locais. Estes compartimentos foram definidos como:

a) Superfície Denudacional Elevada, que representa as áreas de cimeira da bacia, onde predominam os maiores índices de erosão;

b) Superfície Denudacional Intermediária, que atua como área de fornecimento e recebimento de sedimentos;

c) Superfície Denudacional/Agradacional, sendo a que mais recebe sedimentos das áreas mais elevadas, porém promove a retirada de sedimentos através de atuação maior da erosão laminar.

\section{Solos}

A diversificação do relevo favorece uma grande variedade de solos, ocorrendo desde solos bem desenvolvidos, como os Latossolos e os Argissolos, a solos menos desenvolvidos, como Neossolos Litólicos distróficos e eutróficos.

Encontram-se ainda presentes na área solos do tipo Cambissolo distrófico e eutrófico com texturas pedregosa e média cascalhenta em relevo ondulado e forte ondulado.

\section{Cobertura Vegetal}

Com relação ao domínio vegetacional, a área encontra-se situada no domínio fitogeográfico denominado Savana/cerrado por Magnago et al (1983). Na área de estudo, predomina uma paisagem fitogeográfica bastante alterada pela inserção de pastagens artificiais. As áreas de vegetação nativa remanescentes, embora alteradas, estão ao longo de alguns cursos d'água (matas ciliares) e nos interflúvios, associadas a solos pouco desenvolvidos com alguns resquícios de Floresta Estacional preservadas em médias vertentes e em solos mais desenvolvidos. 


\section{Clima}

A área de estudo está inserida no clima tropical subúmido do tipo Aw (Köppen, 1948), com um período seco (abril a setembro) e outro chuvoso (outubro a março),

De acordo com dados do Sistema Meteorológico de Goiás (SIMEGO), nos municípios que formam a bacia, a precipitação média varia de $(1400$ $1600 \mathrm{~mm} / \mathrm{ano}$ ). Os meses de junho a agosto são os mais secos e os meses de fevereiro, março, novembro e dezembro, os mais chuvosos. A temperatura média é de cerca de $25,24^{\circ} \mathrm{C}$, a maior temperatura é atingida geralmente nos meses de agosto a setembro, e as menores, entre junho e julho.

\section{Capacidade de uso das terras na bacia do ribeirão Santo Antônio}

O estudo da capacidade de uso das terras tem por finalidade o planejamento de ações que venham ao encontro do potencial ecológico, econômico e produtivo dos solos, levando, a cada local, técnicas de cultivo e de manejo adequados à sua aptidão. Dentre os maiores problemas relacionados ao uso das terras destaca-se, o risco de erosão, fato comum nas terras cultivadas sem planejamento, onde, muitas vezes, a recuperação se torna inviável ou até impossível.

É preciso considerar, além dos solos, o declive que associado com a falta ou precariedade da cobertura vegetal e com os índices e intensidades de chuva, pode provocar processos erosivos em maior ou menor grau.

Os solos com declive muito acentuado, por exemplo, tem capacidade de uso, no máximo, para pastagens ou reflorestamento, sendo desaconselhável o uso com culturas anuais, que necessitam revolvimento anual com arado. (LEPSCH, 2000, p. 169).

Neste estudo, foi feita uma avaliação parcial da capacidade à erosão laminar dos solos, utilizando-se a metodologia de Salomão (1995) que propõe a determinação da erodibilidade dos solos que no presente estudo, foi determinada através da identificação dos solos da bacia estudada e posteriormente, definida segundo o seu grau, com base nos estudos realizados por Bertoni e Lombardi Neto (1985) para os solos, do Estado de São Paulo. Uma vez conhecidos os índices relativos de erodibilidade de cada tipo de solo fezse o cruzamento das classes de erodibilidade com as classes de declividades encontradas para a bacia, através do mapa de declividades. 
Definidas as classes de suscetibilidade à erosão laminar foram definidas as classes de capacidade de uso das terras conforme metodologia de Lepsch (2000).

As classes de capacidade de uso das terras foram elaboradas com base no mapa de suscetibilidade à erosão laminar, no qual cada classe de suscetibilidade corresponde a uma ou mais classes de capacidade de uso da terra. Por exemplo, a classe de suscetibilidade I (Extremamente suscetível) equivale às classes de capacidade de uso VII e VIII de Lepsch (op cit), ou seja, terras com limitações permanentes mais severas, mesmo quando ocupadas com pastagens e terras nas quais não é aconselhável qualquer tipo de lavoura, pastagens ou florestas comerciais e devem ser reservadas para proteção da fauna e flora silvestre ou recreação controlada.

A seguir, tem-se a relação entre as classes de suscetibilidade à erosão laminar e sua relação com as classes de capacidade de uso das terras.

- A classe I de suscetibilidade (Extremamente suscetível), corresponde às classes VII e VIII de capacidade de uso das terras;

- A classe II de suscetibilidade (Muito Suscetível), corresponde à classe VI de capacidade de uso das terras;

- A classe III de suscetibilidade (Moderadamente Suscetível), corresponde à classe IV de capacidade de uso das terras;

- A classe IV de suscetibilidade (Pouco Suscetível), corresponde à classe III de capacidade de uso das terras;

- A classe V de suscetibilidade (Pouco a Não Suscetível), corresponde às classes I, II, e V de capacidade de uso das terras.

A utilização dos critérios de capacidade de uso das terras deve sempre vir seguida de práticas de manejo e conservação, condizentes com cada caso, além de uma preocupação séria com o cumprimento da legislação ambiental, principalmente no que diz respeito às áreas de preservação permanente.

Tendo como base o mapa de uso e ocupação atual do solo (Figura 2), foi possível estabelecer se o uso atual é ou não compatível com a suscetibilidade erosiva da área, conforme estabelece Salomão (1995).

A cobertura vegetal reflete o nível de proteção do solo em função da ação das chuvas e, consequentemente à erosão, enquanto a ação antrópica indica as áreas mais sujeitas à erosão laminar, pois o uso mais intensivo aumenta o potencial de perda de solo. Com base nisso, são estabelecidas as seguintes classes de uso e ocupação do solo: 
Classe I : cobertura vegetal de baixo e médio porte, com intensa atividade antrópica (culturas anuais, estradas e áreas urbanizadas);

Classe II: cobertura vegetal de baixo e médio porte, com atividade antrópica moderada (culturas perenes, cana-de-açúcar e pastagens);

Classe III - cobertura vegetal de baixo a médio porte, com atividade antrópica muito reduzida (pasto sujo e campo cerrado);

Classe IV - cobertura vegetal de porte alto a médio, com atividade antrópica muito reduzida (reflorestamento, capoeirão e florestas);

Classe V - espelhos d'água e várzeas, cujo potencial erosivo pode ser considerado nulo.

O mapa de suscetibilidade à erosão laminar foi construído com base na metodologia de Salomão (1995), sendo este mapa resultante do cruzamento entre solos declividade.

Cruzando a suscetibilidade à erosão laminar com as classes de ocupação atual das terras, se obtveram as classes de potencial atual à erosão laminar. Em função da generalização determinada pela escala de trabalho (1:100.000), a classe II (ocupação atual das terras) foi a que se destacou, e ao ser cruzada com as classes de suscetibilidade à erosão laminar estabelecidas para a bacia, resultou em três classes de potencial atual à erosão laminar, conforme o quadro abaixo.

Quadro 1. Classes de potencial atual à erosão laminar na Bacia do Ribeirão Santo Antônio.

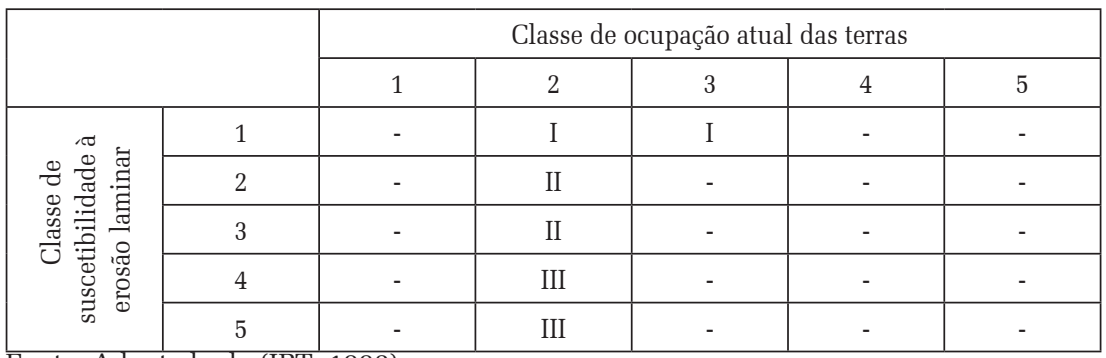

Fonte: Adaptado do (IPT, 1990).

O principal uso na bacia do Ribeirão Santo Antônio é a pastagem, que ocupa $75 \%$ do total da área. Na maior parte da bacia, a vegetação é de pequeno a médio porte em função das próprias características morfológicas do domínio do cerrado, onde se insere a bacia. 
Observando o quadro acima, temos os seguintes potenciais:

Quando cruzada a classe I de suscetibilidade à erosão laminar (extremamente suscetível), com as classes II e III de ocupação atual, obteve-se uma classe I de potencial atual, que representa um alto potencial, onde o uso atual do solo é incompatível com a suscetibilidade à erosão laminar. Estas áreas deveriam estar completamente preservadas. Em alguns pontos a vegetação nativa está de certa forma preservada, porém de forma descontínua em relação ao que deveria ser.

A classe II (Muito Suscetível) de suscetibilidade, quando cruzada com a classe II de ocupação atual, resultou numa classe II de potencial atual à erosão laminar, que apresenta médio potencial, significando um uso atual do solo incompatível com a suscetibilidade à erosão laminar, mas que pode ser controlada com práticas conservacionistas adequadas.

A classe III (Moderadamente Suscetível) de suscetibilidade, quando cruzada com a classe II de ocupação atual, resultou numa classe II de potencial atual à erosão laminar, com médio potencial, como descrito acima.

As classes de suscetibilidade à erosão laminar IV e V (Pouco Suscetível e Pouco a Não Suscetível respectivamente), quando cruzadas com a classe II de ocupação atual, resultaram na classe III de potencial atual à erosão laminar, ou seja, baixo potencial com um uso atual compatível com a suscetibilidade à erosão laminar.

Diante das análises e cruzamentos dos mapas temáticos foi possível perceber que a bacia do Ribeirão Santo Antônio apresenta sérias restrições quanto à sua ocupação e uso. As áreas com restrições em função do potencial atual à erosão laminar compreendem cerca de $70 \%$ do total de área da bacia.

Quanto ao tipo de uso recomendado, percebe-se que, de maneira geral, a bacia do Ribeirão Santo Antônio necessita de um planejamento que atenda a sua potencialidade econômica juntamente com a preservação de seus recursos naturais, principalmente água e solos.

A Figura 3 mostra a capacidade de uso das terras na bacia, enquanto o Quadro 2 mostra as porcentagens da bacia e suas aptidões de uso segundo suas características físicas.

A porcentagem da bacia ocupada por pastagens supera o limite recomendado para este tipo de uso, ou seja, pelas recomendações segundo a capacidade de uso das terras, apenas aproximadamente $50 \%$ da área total da bacia poderia estar ocupada com pastagens, que no uso atual compreende $75 \%$. 
Quadro 2. Uso recomendado segundo a capacidade de uso da terra.

\begin{tabular}{|l|c|c|}
\hline \multicolumn{1}{|c|}{ Uso Recomendado } & $\begin{array}{c}\text { Classe relativa de capacidade } \\
\text { de uso da terra }\end{array}$ & (\%) da Bacia \\
\hline Silvicultura, com restrições para pastagens. & VI & 42 \\
\hline Preservação permanente/Reflorestamento & VII e VIII & 10 \\
\hline Pastagens e culturas perenes & III & 3 \\
\hline Área com restrição parcial a qualquer cultivo & IV & 25 \\
\hline Área favorável para lavouras e pastagens & I, II, e V & 20 \\
\hline
\end{tabular}

Fonte: Adaptado de (LEPSC, 2000).

\section{Conclusões}

A irregularidade do relevo tem bastante influência sobre o uso da terra, pois, embora, na totalidade predomine, declividades mais amenas, as mesmas não são contínuas, nem mesmo a sua extensão é suficiente para um plantio de culturas temporárias, principalmente as de exportação, sendo estas, cultivadas esporadicamente e em pequena proporção dentro da bacia.

$\mathrm{O}$ uso da terra por pastagem se deve, principalmente, à irregularidade do relevo e a pouca extensão de solos bem desenvolvidos.

A declividade na bacia do Ribeirão Santo Antônio é bastante variada, porém predominam declividades entre 0 e 3\% com cerca de 56\% da área total da bacia, mas, esta classe de declividade não favorece o plantio de culturas temporárias que ocupem grandes extensões de terra, devido à descontinuidade ao longo da bacia. Embora as declividades mais acentuadas (acima de 20\%), ocupem apenas 7\% da área total da bacia, o relevo é bastante irregular, o que favorece uma variedade de tipos de solos.

As chuvas na região da bacia são concentradas em alguns meses específicos e, na totalidade, apresentam índices anuais bastante variáveis.

Outra observação importante refere-se à inexpressiva presença de vegetação nativa na bacia. As matas ciliares são descontínuas, não obedecem às faixas de largura estabelecidas pelo Código Florestal Brasileiro, sem contar a ausência de áreas destinadas à reserva legal, que não atinge os $20 \%$ recomendados.

A má conservação da vegetação nativa e dos solos favorece a erosão laminar, sendo que cerca de $52 \%$ da bacia apresenta suscetibilidade erosiva que vai de muito forte a extremamente forte, carecendo um melhor manejo para a área. 
A erosão linear aparece, predominantemente, na forma de sulcos e ravinas favorecidos pela má conservação dos solos e pela ausência de cobertura vegetal nativa.

De maneira geral, a bacia apresenta uma boa potencialidade ao uso econômico, porém é preciso que o seu uso seja bem planejado, seguindo os critérios de capacidade de uso das terras e utilizando os devidos procedimentos de manejo.

\section{Referências}

BERTONI, J. \& LOMBARDI NETO, F. - Conservação do Solo. Piracicaba/SP: Livroceres, 1985.

INSTITUTO DE PESQUISAS TECNOLÓGICAS DO ESTADO DE SÃO PAULO. Orientações para o combate à erosão no Estado de São Paulo: Bacia do Prado Grande> São Paulo, 1990.

KöPPEN, W. Climatología: com un Estúdio de los climas de la Tierra. Fundo de Cultura Económica. México, 1948.

LEPSCH, I. Conservação dos solos. São Paulo: Caderno de textos, 2002.

MAGNAGO, H., SILVA, M. T. M. da, FONZAR, B. C. - Vegetação: as regiões fitoecológicas, sua natureza e seus recursos econômicos. Projeto Radambrasil. (Folha SE.22 - Goiânia). Rio de Janeiro: MME, 1983. (Levantamento de Recursos Naturais 31).

MORETON, Luiz Carlos. Programa Levantamentos geológicos Básicos do Brasil. Iporá. (Folha SE.22-V-B). Escala 1:250.000. Estado de Goiás. Brasília: CPRM, 1999.

SALOMÃO, F. X. de T. Controle e prevenção dos processos erosivos. In: Erosão e Conservação dos solos. Jurandir L. S. Ross (org). São Paulo: Edusp, 1995.

Flávio Alves Souza - Prof. Ms. do curso de geografia da Universidade Estadual de Goiás (UEG) Iporá

Claúdia Valéria Lima - Professora Dra. do curso de geografia da Universidade Federal de Goiás

Recebido para publicação em agosto de 2007 Aceito pra publicação em novembro de 2007 